Full length article

\title{
Comparing the predictive capability of self-report and medically-verified non-fatal overdose in adults released from prison: A prospective data linkage study
}

\author{
Claire Keen ${ }^{\mathrm{a}, *}$, Stuart A. Kinner ${ }^{\mathrm{a}, \mathrm{b}, \mathrm{c}, \mathrm{d}, \mathrm{e}}$, Rohan Borschmann ${ }^{\mathrm{a}, \mathrm{b}, \mathrm{f}, \mathrm{g}}$, Jesse T. Young ${ }^{\mathrm{a}, \mathrm{b}, \mathrm{h}, \mathrm{i}}$ \\ ${ }^{a}$ Justice Health Unit, Centre for Health Equity, Melbourne School of Population and Global Health, The University of Melbourne, Parkville, Victoria, Australia \\ ${ }^{\mathrm{b}}$ Centre for Adolescent Health, Murdoch Children's Research Institute, Parkville, Victoria, Australia \\ ${ }^{\mathrm{c}}$ Mater Research Institute-UQ, University of Queensland, Brisbane, Queensland, Australia \\ ${ }^{\mathrm{d}}$ Griffith Criminology Institute, Griffith University, Brisbane, Queensland, Australia \\ ${ }^{\mathrm{e} S c h o o l ~ o f ~ P o p u l a t i o n ~ a n d ~ P u b l i c ~ H e a l t h, ~ U n i v e r s i t y ~ o f ~ B r i t i s h ~ C o l u m b i a, ~ V a n c o u v e r, ~ B C, ~ C a n a d a ~}$ \\ ${ }^{\mathrm{f}}$ Health Service and Population Research Department, Institute of Psychiatry, Psychology \& Neuroscience, King's College London, London, UK \\ ${ }^{\mathrm{g}}$ Melbourne School of Psychological Sciences, The University of Melbourne, Melbourne, Victoria, Australia \\ ${ }^{\mathrm{h}}$ School of Population and Global Health, The University of Western Australia, Perth, Western Australia, Australia \\ ${ }^{i}$ National Drug Research Institute, Curtin University, Perth, Western Australia, Australia
}

\section{A R T I C L E I N F O}

\section{Keywords:}

Drug overdose

Self-report

Linked data

Prisons

Cohort studies

\begin{abstract}
A B S T R A C T
Background: Self-reported non-fatal overdose (NFOD) is a predictor of future overdose and is often used to target overdose prevention for people released from prison. However, the level of agreement between self-reported and medically-verified NFOD history remains unknown. This study aimed to determine the agreement between, and predictive value of, self-reported and medically-verified history of NFOD in people recently released from prison. Methods: Pre-release baseline survey data from 1307 adults in prison surveyed from 2008 to 2010 in Queensland, Australia were linked to ambulance, emergency department, and hospital records. We compared the agreement of self-reported NFOD history in the baseline survey and medically-verified NFOD ascertained through linked medical data. Unadjusted and adjusted regression models were used to determine the association between self-reported and medically verified NFOD history and medically-verified NFOD after release from prison.

Results: 224 (19\%) participants self-reported NFOD history only, 75 (5 \%) had medically-verified NFOD history only, and 56 (4\%) both self-reported and had medically-verified NFOD history. Compared to those with no NFOD history, those who self-reported and had a medical history of NFOD (adjusted hazard ratio (AHR) $6.1,95$ \%CI 3.1-11.9), those with a medical history only (AHR 3.4, $95 \%$ CI 1.7-7.0), and those who self-reported only (AHR 1.8, 95 \%CI 1.0-3.5) were at increased risk of medically-verified NFOD after release from prison.

Conclusions: Relying on self-report of NFOD is likely to miss people at increased risk of future NFOD, many of whom could be identified through medical records. Wherever possible, data related to NFOD should be triangulated from multiple sources.
\end{abstract}

\section{Introduction}

There is a disproportionate incidence of drug overdose after release from prison (Binswanger et al., 2007; Darke and Ross, 1996; Hobbs et al., 2006; Pollini et al., 2006). Drug-related deaths in people released from prison contribute substantially to the total number of drug-related deaths (Coffey et al., 2003; Massachusetts Department of Public Health, 2017; Nosrati et al., 2019). Given the high risk of overdose following release from custody, some prisons have implemented overdose prevention and harm minimisation programs, including the provision of take-home naloxone (an opioid antagonist which reverses the effect of opioid overdose) (Strang et al., 2013) and targeted post-release support (Provincial Health Services Authority, 2019). Such programs often target those who report a history of non-fatal overdose (NFOD), a strong risk factor for subsequent fatal (Caudarella et al., 2016; Stoové et al., 2009) and non-fatal overdose (Coffin et al., 2007; Darke et al., 2014; Kinner et al., 2012; Winter et al., 2015). Therefore, assessing whether self-reported NFOD history is an accurate predictor of future

\footnotetext{
* Corresponding author at: Justice Health Unit, The University of Melbourne, Level 4, 207 Bouverie Street, Carlton, VIC, 3010, Australia.

E-mail address: Claire.keen@unimelb.edu.au (C. Keen).
} 
overdose is important to ensure that prevention measures are effectively targeted to those at increased risk.

However, there are very few, if any, objective definitions of NFOD. Most studies have ascertained overdose through self-report (Colledge et al., 2019; Martins et al., 2015). Self-reported drug use, illegal behaviour, and risk-taking behaviour have been found to be reasonably reliable in people who use drugs (Darke, 1998). However, self-report is, by definition, subjective, and can be influenced by recall and social desirability bias (Kerr et al., 2007). Further, the definition and ascertainment of NFOD by studies using self-report have varied considerably (Colledge et al., 2019). Some studies have limited their definition of overdose to those involving opioids (Brugal et al., 2002; Stoové et al., 2009; Yin et al., 2007), while others have left NFOD undefined and open to participant interpretation (Best et al., 2000; Kerr et al., 2007; Lake et al., 2015; Milloy et al., 2008; Neale and Robertson, 2005; Powis et al., 1999; Winter et al., 2015). Limiting studies to people who report illicit opioid use or limiting the definition of overdose to events involving symptoms common in opioid overdose implicitly limits the ascertainment of NFOD to opioid overdoses (Coffin et al., 2007; Fischer et al., 2004; Hakansson, 2008; Jenkins et al., 2011; Maloney et al., 2009; Pollini et al., 2006; Rafful et al., 2018).

An alternative, and arguably more objective, method of identifying overdose is through administrative data. However, medical service data can substantially under-ascertain NFOD events; only about half of NFODs are attended by an ambulance, and fewer still involve hospital contact (Fischer et al., 2004; McGregor et al., 1998; Milloy et al., 2010; Ochoa et al., 2005; Pollini et al., 2006; Wakeman et al., 2009). People experiencing NFOD may not require emergency care, particularly in settings with adequate coverage of take-home naloxone (Banjo et al., 2014; Bennett et al., 2011; Enteen et al., 2010; Seal et al., 2003; Tobin et al., 2009). They may also avoid health service contact for fear of police involvement (Bennett et al., 2011; Davidson et al., 2002; McGregor et al., 1998; Seal et al., 2003; Tracy et al., 2005). Therefore, measuring NFOD solely through administrative data will underascertain NFOD events.

Further, while most studies using emergency department (ED) and hospital records define NFOD using the International Classification of Disease (ICD) codes for drug poisoning (Australian Institute of Health and Welfare, 2016; Centers for Disease Control and Prevention, 2013, 2017; Lloyd et al., 2017), chart reviews have shown that many cases of NFOD are not coded as drug poisoning (Reardon et al., 2016; Slavova et al., 2015, 2014). In one US study, International Classification of Disease 9th Edition, Clinical Modification (ICD-9-CM) codes for opioid poisoning identified opioid overdoses with $25 \%$ sensitivity compared to chart review (Rowe et al., 2017).

Response to naloxone in ambulance or other medical care has also been used as a proxy measure for overdose (Dietze et al., 2000; Gunasekaran et al., 2018; Ray et al., 2018). However, the use of naloxone may be low (Darke and Ross, 1996; Darke et al., 2007; McGregor et al., 1998; Yin et al., 2007), the decision to administer naloxone can be subjective (Sumner et al., 2016), and, by definition, response to naloxone limits NFOD to events involving opioids. Overdoses caused by other drugs, including benzodiazepines, barbiturates, alcohol, and cocaine, occur (Degenhardt et al., 2003; Kaye and Darke, 2004; Kinner and Degenhardt, 2008; Mesquita et al., 2001) and are associated with a range of health problems (Darke et al., 2008; Kaye and Darke, 2004). The low frequency of non-opioid overdoses recorded in research could be, in part, a reflection of the limited capacity for overdose definitions to capture non-opioid overdose (Rafful et al., 2018).

To our knowledge, no study has directly compared the agreement between self-reported and medically-verified NFOD history. Therefore, applying commonly used definitions of self-report and medically-verified NFOD, this study aimed to: 1) determine the level of agreement between self-reported history of NFOD and medically-verified history of NFOD in people recently released from prison; and 2) examine the extent to which self-reported history of NFOD and/or a medically- verified history of NFOD predict the occurrence of future medicallyverified NFOD in this population.

\section{Methods}

Participants were 1325 adults ( $\geq 18$ years) recruited to the Passports study, a randomised controlled trial of a low-intensity casemanagement intervention designed to increase primary care and mental healthcare engagement after release from prison (Kinner et al., 2013). Adults within six weeks of expected release from prison were recruited from seven prisons in Queensland, Australia. This cohort was found to be representative of all releases in Queensland during the recruitment period, on assessed demographic and criminal justice variables (Kinner et al., 2013). Participants completed a baseline survey between August 2008 and July 2010 including demographic information, physical and mental health, substance use before and during incarceration, and other health-related risk behaviours. Participants were contacted to complete follow-up interviews addressing similar topics approximately one, three, and six months after release from prison. Survey data were probabilistically linked, retrospectively and prospectively, to state-wide ambulance (1 January 2007 - 1 January 2014), ED (1 June 2002 - 31 July 2012), and hospital admission records (1 July 1999 - 31 July 2012), and prospectively to national medication dispensing (Pharmaceutical Benefits Scheme (PBS)) (1 August 2008 - 31 May 2013), and National Death Index (1 August 2008 - 31 May 2013) records. Comparable data linkage processes have been shown to produce false-positive and false-negative rates less than $0.1 \%$ (Boyd et al., 2012; Lawrence et al., 2008; Preen et al., 2004). The linkage included all known aliases, considered the gold standard for linkage involving vulnerable populations (Larney and Burns, 2011; Tibble et al., 2018). State-wide correctional records and prison medical records (1 July 2006 - 31 December 2013) were deterministically linked using a unique prisoner identification number. All participants provided written, informed consent.

\subsection{Measures}

During the baseline survey participants were asked: "Have you ever overdosed or become unconscious as a result of taking drugs?". This definition was intentionally left broad, to accommodate poly-drug use, consistent with previous research (Fischer et al., 2004; Kerr et al., 2007; Moore et al., 2013; Winter et al., 2015). Participants who answered 'yes' were recorded as reporting NFOD history. Those who answered 'no', or where an answer was missing, were recorded as having no selfreported NFOD history.

We created a medically-verified NFOD indicator using ambulance, ED and hospital admission data. Ambulance events were considered NFOD events if the participant was administered naloxone or the case description indicated drug use and overdose. ED events were considered NFOD events if they had a principal diagnosis related to drug poisoning (ICD $10^{\text {th }}$ Edition, Australian Modification (ICD-10-AM):T36T50) or the clinical case notes indicated drug use and overdose. Hospital admissions were classified as NFOD events if any diagnosis or external cause of injury was coded as a drug poisoning (ICD-10AM:T36-T50, X40-X44, Y10-Y14, X60-X64, X85). This definition was similar to that used in previous studies focused on overdose from any drug (Slavova et al., 2014). We included data from multiple medical services to increase the capture of NFOD events (MacDougall et al., 2019; Massachusetts Department of Public Health, 2017). To minimise over-counting, NFOD events occurring within the same calendar day were counted as a single event. Given the focus in the literature on opioid overdose, we created a secondary definition, used in sensitivity analyses, that was limited to opioid-related overdoses. This definition required clinical notes to mention opioid consumption, the person to have responded to naloxone administration, or a recorded diagnosis of opioid poisoning (ICD-10-AM:T40.0-T40.4). The self-report measure of 
NFOD was not altered in sensitivity analyses. An indicator of one or more previous medically-verified NFOD was created using events before the date of baseline survey. The median duration of retrospective data for each data source is provided in Supplementary Table S1.

We created four mutually-exclusive NFOD history categories, based upon the baseline self-report and retrospectively linked health records. The categories were: (1) no self-reported or medically-verified NFOD history ("no history"); (2) self-reported NFOD history without medically-verified NFOD history ("self-reported only"); (3) no self-reported NFOD history but one or more medically-verified NFOD events before baseline ("medically-verified only"); and (4) self-reported NFOD history and one or more medically-verified NFOD events before baseline ("selfreported and medically-verified"). Neither the absence of a medicallyverified NFOD nor a failure to self-report NFOD was understood to indicate the unequivocal absence of previous NFOD.

Medically-verified NFOD during follow-up was recorded using the same method. Follow-up began on the day of release from the index incarceration (i.e., the incarceration during which they were recruited) and was censored at 31 July 2012 to ensure complete coverage of all data sources.

\subsection{Data analysis}

We calculated descriptive statistics for all measures and used Pearson's chi-squared test to compare baseline characteristics across the NFOD categories. To estimate the agreement between self-report and medically-verified NFOD, we calculated prevalence- and bias-adjusted kappa statistics (Chen et al., 2009) and average positive and negative agreement (Cicchetti and Feinstein, 1990; Looney and Hagan, 2007). Kappa statistics of 0.21-0.40, 0.41-0.60, 0.61-0.80, and 0.81-1.00 are considered to represent "Fair", "Moderate", "Substantial" and "Almost perfect" agreement respectively (Landis and Koch, 1977).

We calculated crude incidence rates and $95 \%$ confidence intervals (95 \%CIs) for medically-verified NFOD after release, overall and for each NFOD category. We fitted a Kaplan-Meier plot with follow-up censored at the first of: first NFOD after index release, death, or end of follow-up, to estimate the conditional probability of survival to studyend without a medically-verified NFOD. To assess the time-dependent nature of NFOD after release from prison, we estimated the piecewise incidence of NFOD after index incarceration stratified by baseline NFOD category. We estimated the risk of medically-verified NFOD after release from index incarceration by fitting univariate and multivariate Andersen-Gill models with robust error variance, to account for correlation between recurrent events (Andersen and Gill, 1982). We adjusted the multivariate model for selected demographic, health, social, and criminal justice factors that have previously been associated with NFOD (Kerr et al., 2007; Kinner et al., 2012). The included covariates are listed with their operational definitions in Supplementary Table 2. Missing covariates were imputed using multiple imputation (see supplementary material). To compare hazard rates between baseline NFOD categories in the adjusted model, we conducted post-hoc pairwise comparisons using Šidák's method to adjust for multiple comparisons (Šidák, 1967). Sensitivity analyses are described in the supplementary material. All analyses were conducted using Stata v14.2 (StataCorp, 2015).

\subsection{Ethics}

This study was approved by the University of Queensland's Behaviour and Social Sciences Ethical Review Committee (Project \#2007000607), Queensland Corrective Services Research Committee, Queensland Department of Health Human Research Ethics Committee (HREC/11/QHC/40), and Australian Institute of Health and Welfare Ethics Committee (EC2012/4/58).
Table 1

Proportions of participants assigned to each baseline non-fatal overdose category.

\begin{tabular}{llll}
\hline Self-report & \multicolumn{2}{l}{ Medically-verified } & \multirow{2}{*}{ Total } \\
\cline { 2 - 3 } & No & Yes & \\
\hline No & $936(72 \%)$ & $71(5 \%)$ & $1007(77 \%)$ \\
Yes & $244(19 \%)$ & $56(4 \%)$ & $300(23 \%)$ \\
Total & $1180(90 \%)$ & $127(10 \%)$ & $1307(100 \%)$ \\
\hline
\end{tabular}

\section{Results}

We excluded 18 participants whose health records were not linked $(\mathrm{n}=10)$ or who were not released from prison during follow-up $(\mathrm{n}=8)$. Of the 1307 participants $(98.7 \%)$ included in analyses, 1030 (79\%) were male, 973 (74\%) were aged less than 25 years at baseline, 728 (56 \%) reported previous injecting drug use, and 690 (53\%) had a previous mental illness and/or substance use diagnosis.

\subsection{History of non-fatal overdose}

Three-hundred (23\%) participants reported a history of NFOD at baseline and 127 (10\%) had at least one medically-verified NFOD recorded prior to their index release from prison. Eight participants $(0.6$ $\%$ ) were missing a response to the self-report of NFOD baseline question and were recoded as no self-reported NFOD history. Table 1 presents the relationship between self-reported and medically-verified NFOD. Of the 127 participants with medically-verified NFOD history, 56 (44\%) reported NFOD history at baseline, while 71 (56 \%) did not report NFOD history. Of the 1180 participants with no medically-verified NFOD history, 244 (21\%) reported NFOD history, and 936 (79 \%) did not report NFOD history.

The prevalence- and bias-adjusted agreement between self-reported and medically-verified NFOD was estimated at 0.52 (95\% confidence interval [CI] 0.47-0.56), indicating moderate agreement between selfreported and medically-verified NFOD. The average positive agreement was estimated at 0.26 (95\% $\%$ CI $21-0.32$ ), indicating fair agreement between self-report and medical records when attributing a history of NFOD. The average negative agreement was estimated at $0.86(95 \% \mathrm{CI}$ 0.84-0.87), indicating almost perfect agreement in attributing a lack of NFOD history using self-report and medical records. Of the participants with medically-verified NFOD history, $42 \%$ (32/75) of those with one medically-verified NFOD, $44 \%(11 / 25)$ of those with two medicallyverified NFOD, and $67 \%(10 / 15)$ of those with three or more medically-verified NFOD reported NFOD history. Twenty-six (20\%) had NFOD history recorded through ambulance data, 61 (48 \%) through ED data, and 99 (78 \%) through hospital data. Table 2 displays the baseline characteristics of the cohort according to NFOD category.

Thirty-five deaths occurred during follow-up. Eighteen (2\%) participants with no NFOD history (crude mortality rate (CMR) 6.6, $95 \% \mathrm{CI}$ 4.2-10.5 per 1000 person-years); 8 (3\%) participants with self-reported NFOD history only (CMR 11.3, 95 \%CI 5.6-22.6); 5 (7 \%) participants with medically-verified NFOD history only (CMR 24.5, $95 \% \mathrm{CI}$ 10.2-58.8); and < 5 participants with both self-reported and medicallyverified NFOD history (CMR 25.0, 95 \%CI 9.4-66.6) died during followup. There were 11 overdose deaths during follow-up.

\subsection{NFOD after release from prison}

A total of 108 (8\%) participants experienced 181 NFOD events during 3804 person-years of follow-up (median 2.9 years, interquartile range (IQR) 2.5-3.4 years of follow-up). Of the 181 medically-verified NFOD events during follow-up, 59 (33\%) involved ambulance attendance, 123 (68\%) involved ED attendance, and 71 (39\%) involved hospital admission. Table 3 presents the proportion of participants with 
Table 2

Baseline characteristics of participants by NFOD category.

\begin{tabular}{|c|c|c|c|c|c|c|}
\hline & \multirow[t]{2}{*}{ Total $(\mathrm{N})$} & \multicolumn{4}{|l|}{ NFOD history (n, \%) } & \multirow[t]{2}{*}{ p-value } \\
\hline & & Self-report and medically-verified & Medically-verified only & Self-report only & No history & \\
\hline \multicolumn{7}{|l|}{ Demographic } \\
\hline \multicolumn{7}{|l|}{ Age at release } \\
\hline$<25$ years & 334 & $4(1 \%)$ & $14(4 \%)$ & $62(19 \%)$ & $254(76 \%)$ & 0.006 \\
\hline$\geq 25$ & 973 & $52(5 \%)$ & $57(6 \%)$ & $182(19 \%)$ & $682(70 \%)$ & \\
\hline \multicolumn{7}{|l|}{ Sex } \\
\hline Female & 277 & $27(10 \%)$ & $24(9 \%)$ & $41(15 \%)$ & $185(67 \%)$ & $<0.001$ \\
\hline Male & 1030 & $29(3 \%)$ & $47(5 \%)$ & $203(20 \%)$ & $751(73 \%)$ & \\
\hline \multicolumn{7}{|l|}{ Indigeneity } \\
\hline Not Indigenous & 976 & $46(5 \%)$ & $57(6 \%)$ & $188(19 \%)$ & $685(70 \%)$ & 0.198 \\
\hline Indigenous & 331 & $10(3 \%)$ & $14(4 \%)$ & $56(17 \%)$ & $251(76 \%)$ & \\
\hline \multicolumn{7}{|l|}{ Education } \\
\hline$\geq 10$ years & 744 & $28(4 \%)$ & $38(5 \%)$ & $124(17 \%)$ & $554(75 \%)$ & 0.069 \\
\hline$<10$ years & 563 & $28(5 \%)$ & $33(6 \%)$ & $120(21 \%)$ & $382(68 \%)$ & \\
\hline \multicolumn{7}{|c|}{ Employment status a } \\
\hline Employed & 662 & $12(2 \%)$ & $35(5 \%)$ & $100(15 \%)$ & $515(78 \%)$ & $<0.001$ \\
\hline Unemployed & 644 & $44(7 \%)$ & $36(6 \%)$ & $144(22 \%)$ & $420(65 \%)$ & \\
\hline Accommodation $^{\mathrm{a}}$ & & & & & & \\
\hline Stable housing & 1084 & $45(4 \%)$ & $56(5 \%)$ & $194(18 \%)$ & $789(73 \%)$ & 0.230 \\
\hline Unstable housing & 220 & $11(5 \%)$ & $15(7 \%)$ & $49(22 \%)$ & $145(66 \%)$ & \\
\hline Perceived social s & & & & & & \\
\hline Mod-high & 1058 & $43(4 \%)$ & $60(6 \%)$ & $178(17 \%)$ & $777(73 \%)$ & 0.003 \\
\hline Low & 249 & $13(5 \%)$ & $11(4 \%)$ & $66(27 \%)$ & $159(64 \%)$ & \\
\hline Removed from fa & a child & & & & & \\
\hline No & 1045 & $39(4 \%)$ & $56(5 \%)$ & $177(17 \%)$ & $773(74 \%)$ & 0.001 \\
\hline Yes & 262 & $17(7 \%)$ & $15(6 \%)$ & $67(26 \%)$ & $163(62 \%)$ & \\
\hline Criminal justice & & & & & & \\
\hline Duration of incar & & & & & & \\
\hline$>365$ days & 268 & $10(4 \%)$ & $8(3 \%)$ & $64(24 \%)$ & $186(69 \%)$ & 0.099 \\
\hline $91-365$ days & 670 & $27(4 \%)$ & $38(6 \%)$ & $120(18 \%)$ & $485(72 \%)$ & \\
\hline$\leq 90$ days & 369 & $19(5 \%)$ & $25(7 \%)$ & $60(16 \%)$ & $265(72 \%)$ & \\
\hline Previous incarcer & & & & & & \\
\hline None & 438 & $9(2 \%)$ & $21(5 \%)$ & $44(10 \%)$ & $364(83 \%)$ & $<0.001$ \\
\hline At least once & 861 & $47(6 \%)$ & $50(6 \%)$ & $197(23 \%)$ & $567(66 \%)$ & \\
\hline Juvenile Detentio & & & & & & \\
\hline None & 946 & $38(4 \%)$ & $56(6 \%)$ & $153(16 \%)$ & 699 (74 \%) & 0.001 \\
\hline At least once & 361 & $18(5 \%)$ & $15(4 \%)$ & $91(25 \%)$ & $237(66 \%)$ & \\
\hline Parole $^{\mathrm{b}}$ & & & & & & \\
\hline No & 1097 & $49(5 \%)$ & $52(5 \%)$ & $207(19 \%)$ & $789(72 \%)$ & 0.054 \\
\hline Yes & 202 & $7(4 \%)$ & 19 (9\%) & $34(17 \%)$ & $142(70 \%)$ & \\
\hline Physical health & & & & & & \\
\hline SF36 PCS & & & & & & \\
\hline$\geq 45^{\mathrm{c}}$ & 174 & $11(6 \%)$ & $11(6 \%)$ & $26(15 \%)$ & $126(72 \%)$ & 0.254 \\
\hline$<45$ & 1114 & $43(4 \%)$ & $59(5 \%)$ & $216(19 \%)$ & $796(72 \%)$ & \\
\hline Hepatitis C & & & & & & \\
\hline Unexposed & 1114 & $43(4 \%)$ & $59(5 \%)$ & $216(19 \%)$ & $796(72 \%)$ & $<0.001$ \\
\hline Exposed & 174 & $11(6 \%)$ & $11(6 \%)$ & $26(15 \%)$ & $126(72 \%)$ & \\
\hline Unknown & 1114 & $43(4 \%)$ & $59(5 \%)$ & $216(19 \%)$ & $796(72 \%)$ & \\
\hline Mental health & & & & & & \\
\hline Suicide attempt ${ }^{\mathrm{d}}$ & & & & & & \\
\hline None & 1030 & $31(3 \%)$ & $44(4 \%)$ & $160(16 \%)$ & 795 (77 \%) & $<0.001$ \\
\hline At least once & 277 & $25(9 \%)$ & $27(10 \%)$ & $84(30 \%)$ & $141(51 \%)$ & \\
\hline Mental disorder s & & & & & & \\
\hline No diagnosis & 617 & $3(1 \%)$ & $2(0.3 \%)$ & $84(14 \%)$ & $528(86 \%)$ & \\
\hline Mental illness & 99 & $2(2 \%)$ & $9(9 \%)$ & $10(10 \%)$ & $78(79 \%)$ & $<0.001$ \\
\hline Substance use & 314 & $13(4 \%)$ & $20(6 \%)$ & $79(25 \%)$ & $202(64 \%)$ & \\
\hline Dual diagnosis & 277 & $38(14 \%)$ & $40(14 \%)$ & $71(26 \%)$ & $128(46 \%)$ & \\
\hline Psychological dist & & & & & & \\
\hline Low-High & 1180 & $47(4 \%)$ & $63(5 \%)$ & $213(18 \%)$ & $857(73 \%)$ & 0.052 \\
\hline Very High & 122 & $9(7 \%)$ & $8(7 \%)$ & $30(25 \%)$ & $75(62 \%)$ & \\
\hline Substance use & & & & & & \\
\hline IDU $^{\mathrm{d}}$ & & & & & & \\
\hline No & 576 & $5(1 \%)$ & $24(4 \%)$ & $38(7 \%)$ & $509(88 \%)$ & $<0.001$ \\
\hline Yes & 728 & $51(7 \%)$ & $47(7 \%)$ & $206(28 \%)$ & $424(58 \%)$ & \\
\hline Drug use in priso & & & & & & \\
\hline No & 885 & $30(3 \%)$ & $45(5 \%)$ & $111(13 \%)$ & $699(79 \%)$ & $<0.001$ \\
\hline Yes & 421 & $26(6 \%)$ & $26(6 \%)$ & $133(32 \%)$ & $236(56 \%)$ & \\
\hline Tobacco depende & & & & & & \\
\hline None-moderate & 1021 & $34(3 \%)$ & $51(5 \%)$ & $168(17 \%)$ & $768(75 \%)$ & $<0.001$ \\
\hline High & 283 & $22(8 \%)$ & $19(7 \%)$ & $76(27 \%)$ & $166(59 \%)$ & \\
\hline Risky alcohol use & & & & & & \\
\hline Low-moderate & 807 & $31(4 \%)$ & $39(5 \%)$ & $139(17 \%)$ & $598(74 \%)$ & 0.105 \\
\hline High & 471 & $25(5 \%)$ & $28(6 \%)$ & $99(21 \%)$ & $319(68 \%)$ & \\
\hline
\end{tabular}


Table 2 (continued)

\begin{tabular}{|c|c|c|c|c|c|c|}
\hline & \multirow[t]{2}{*}{ Total (N) } & \multicolumn{4}{|l|}{ NFOD history (n, \%) } & \multirow[t]{2}{*}{$\mathrm{p}$-value } \\
\hline & & Self-report and medically-verified & Medically-verified only & Self-report only & No history & \\
\hline \multicolumn{7}{|c|}{ Randomisation } \\
\hline Control & 653 & $32(5 \%)$ & $27(4 \%)$ & $113(17 \%)$ & $481(74 \%)$ & 0.064 \\
\hline Intervention & 654 & $24(4 \%)$ & $44(7 \%)$ & $131(20 \%)$ & $455(70 \%)$ & \\
\hline
\end{tabular}

NFOD: non-fatal overdose, IDU: injection drug use, SF36 PCS: Short form 36 physical component summary score.

Due to rounding, percentages may not sum to 100 .

a Prior to index incarceration.

b Index incarceration.

c Categorised at one standard deviation below the sample mean.

d Lifetime prevalence.

1 or more medically-verified NFOD during follow-up, according to baseline characteristics. The crude incidence rates per 1000 person years for each of the NFOD categories were: self-reported and medically-verified 325.1 (95\%CI 247.7-426.6), medically-verified only 132.2 (95 \%CI 90.7-192.8), self-reported only 63.4 (95 \%CI 47.4-85.0), and no history 20.9 (95\%CI 16.1-27.1). In the adjusted model, the adjusted hazard ratio (AHR) of each NFOD category compared to those without medically-verified or self-reported NFOD history were: self-reported and medically-verified 6.1 (95 \%CI 3.1-11.9), medically-verified only 3.4 (95\%CI 1.7-7.0), and self-reported only 1.8 (95 \%CI 1.0-3.5). In a pairwise comparison, there was no difference in hazard rates for participants with self-reported and medically-verified NFOD history and medically-verified NFOD history only $(\mathrm{p}=0.479)$. The full multivariate model is shown in Table 3.

Fig. 1 displays the survival function for medically-verified NFOD in community after release from custody, according to baseline NFOD category. For participants with self-reported and medically-verified NFOD history and medically-verified NFOD history only, the rate of NFOD was highest in the first 28 days after release (Supplementary Figure S2).

\subsection{Sensitivity analyses}

Sensitivity analyses were consistent with our primary analyses. When restricting our analysis to the opioid definition of medicallyverified NFOD, 948 (73\%) participants had no self-reported or medically-verified NFOD history, 227 (21 \%) had self-reported but not medically-verified NFOD history, 11 (1\%) had medically-verified but not self-reported NFOD history, and 23 (2\%) had both self-reported and medically-verified NFOD history. There were 63 medically-verified opioid NFOD during follow-up experienced by 42 participants. The number of people with self-reported and medically-verified NFOD, at baseline and during follow-up, according to baseline NFOD category is shown in Supplementary Table S3. Adjusted hazard ratios for each sensitivity model are shown in Supplementary Table S4. The adjusted hazard of subsequent NFOD for people with medically-verified and no self-reported NFOD history compared to people without any NFOD history was higher when using the opioid definition of NFOD than in the primary analysis (opioid definition AHR $=5.4,95 \%$ CI 1.2-24.5 vs. primary analysis AHR $=3.4,95 \%$ CI 1.7-7.0). Similarly, the adjusted hazard rate of subsequent NFOD for participants with self-reported NFOD history only compared to people without any NFOD history was higher when using the opioid definition of NFOD than in the primary analysis (opioid definition: AHR $=4.1$, $95 \%$ CI $1.7-9.8$ vs primary analysis AHR $=1.8,95 \%$ CI 1.0-3.5).

Results comparing report of NFOD in follow-up surveys and prospectively linked health data are reported in Supplementary Tables S5 \& S6. Of the 1052 participants who completed at least one follow-up survey, 49 (5\%) reported at least one NFOD during follow-up and 26 (2 $\%$ ) had at least one medically verified NFOD. The proportion of people who had self-reported NFOD history only, medically-verified NFOD history only, and both self-reported and medically-verified NFOD history was lower than when using retrospective data and self-report of lifetime NFOD. Of the 26 people with medically-verified NFOD during follow-up, 7 (27\%) self-reported NFOD, while 19 (73\%) did not report NFOD. Of the 1026 participants with no medically-verified NFOD, 42 (4 \%) reported NFOD, and 984 (96\%) did not report NFOD.

\section{Discussion}

To our knowledge this is the first study to compare the agreement and predictive capability of self-reported and medically-verified NFOD. In a large cohort of adults recently released from prison, we observed a high rate of NFOD and found that NFOD history was a strong predictor of subsequent NFOD. The crude NFOD rate was 15-fold higher in those who self-reported and had a medically-verified history of NFOD, 6-fold higher in those with a medical history of NFOD who did not report NFOD history, and 3-fold higher in those who self-reported NFOD but did not have a medically-verified history of NFOD, compared to those with no self-reported or medically-verified history of NFOD.

Among those with medically-verified NFOD history, the risk of subsequent NOFD was higher for those who also self-report NFOD history than those who did not, although this difference was not statistically significant. These findings provide some evidence that individuals who both self-report NFOD history and have a medicallyverified history of NFOD may be at particularly high risk, although replication with larger sample will be required to confirm this. Previous research using this cohort found that self-reported history of NFOD is associated with increased risk of all-cause mortality (Forsyth et al., 2018).

Over half of those with a medically-verified history of NFOD did not report NFOD during the baseline survey. Possible reasons for not reporting NFOD include stigma attached to drug use and overdose, poor recall, and different understandings of overdose. Previous studies asking people who use illicit drugs to describe the symptoms of an overdose have found that the majority of people associate NFOD with symptoms related to opioid overdose (i.e., collapse, turning blue, stopping breathing) (Powis et al., 1999). Therefore, people who experience NFOD without opioid use, or with markedly different symptoms, may not have considered it an overdose.

Individuals with a medically-verified history of NFOD who did not report NFOD were nevertheless at high risk of NFOD during follow-up: $25 \%$ of participants with medically-verified NFOD who did not selfreport NOFD history experienced at least one medically-verified NFOD during follow-up. In an adjusted model, participants with a medicallyverified NFOD history who did not self-report NFOD history were three times more likely than those with no self-reported or medically-verified NFOD history to experience an NFOD during follow-up. Routine access to medical records in prisons and other inpatient settings would improve identification of people at risk, who could be targeted for prevention and transitional treatment and support. In settings where health services in prison are the responsibility of a ministry of justice, 
Table 3

Post-baseline medically-verified NFOD events according to baseline NFOD category and demographic variables.

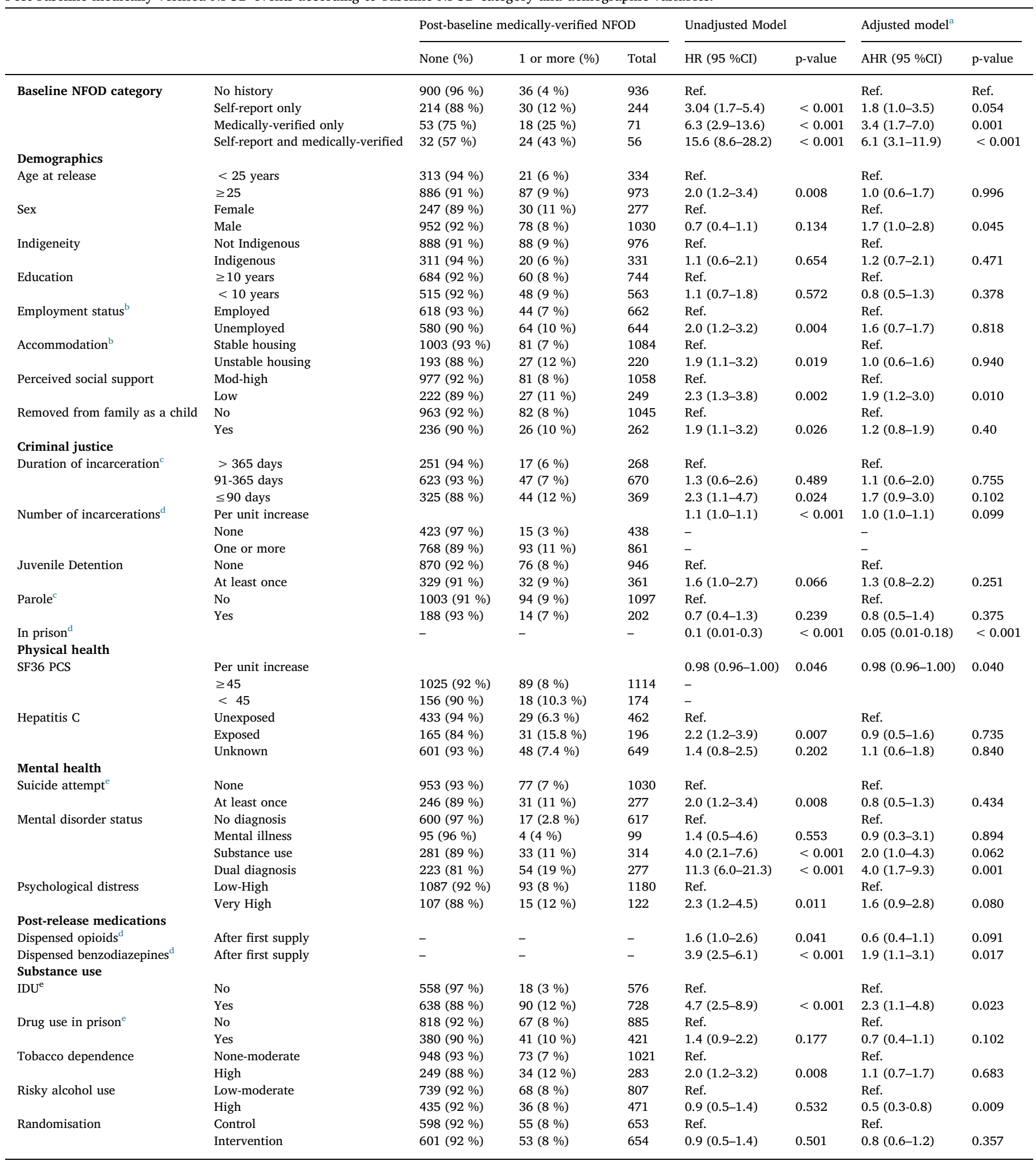

NFOD: Non-fatal overdose, SF36 PCS: Short form 36 physical component summary score, IDU: Injection drug use, HR: hazards ratio, AHR: adjusted hazards ratio, 95 \%CI: $95 \%$ confidence interval.

Due to rounding, percentages may not sum to 100 .

${ }^{\text {a }}$ Adjusted model used multiple imputation.

b Prior to index incarceration.

c Index incarceration.

d Time varying covariate.

e Lifetime prevalence. 

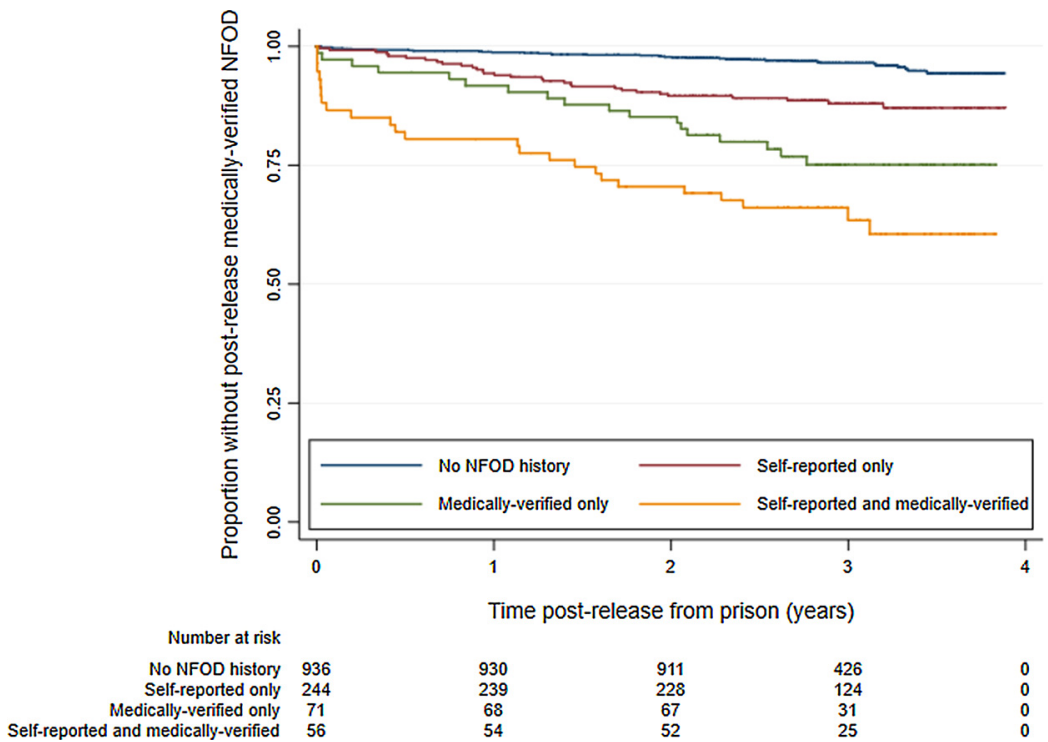

$\begin{array}{cccc}930 & 911 & 426 & 0 \\ 239 & 228 & 124 & 0 \\ 68 & 67 & 31 & 0 \\ 54 & 52 & 25 & 0\end{array}$

Fig. 1. Kaplan-Meier curve of medically-verified non-fatal overdose events following release from prison by baseline non-fatal overdose category.

routine application of algorithms for identifying individuals with a history of overdose would eliminate the need for correctional staff to access detailed medical information. In accordance with WHO recommendations (2013), having prison health services managed and delivered by a ministry of health, rather than a ministry of justice, would further reduce this risk, and could potentially remove barriers to sharing health records between prison and community health settings.

Self-report identified approximately double the number of participants as having NFOD history compared to using medical records. Of the 371 people who were identified through either medical records or self-report to have a history of NFOD, $244(66 \%)$ did not have a medically-verified NFOD history. Therefore, solely using medical records to ascertain previous NFOD would exclude a large proportion of those with NFOD history.

It is possible that some self-report of NFOD resulted in medical care that was not captured in our study. NFOD could have occurred before our retrospective data began, in a different state, or without paramedics or medical services recording the person's identity. It is also likely that many people overdosed without utilising health services. Previous studies have found that up to $50 \%$ of NFOD may not result in medical care (Fischer et al., 2004; McGregor et al., 1998; Milloy et al., 2010; Ochoa et al., 2005; Pollini et al., 2006; Wakeman et al., 2009). This may be due to a lack of willingness to access health services, due to the stigmatisation of drug use or fear of police involvement, or receiving care without the involvement of formal health services. Trials of takehome naloxone have suggested that the utilisation of medical services for overdose may be lower where take-home naloxone is administered (Banjo et al., 2014; Bennett et al., 2011; Enteen et al., 2010). As such, public health messages and training programs for take-home naloxone should include a recommendation to access medical care following a NFOD, even if naloxone is successfully administered (Piper et al., 2008). This would provide an opportunity for NFOD prevention and harm minimisation programs (Banta-Green et al., 2019), improving health outcomes and the ascertainment of NFOD history using medical records.

No single medical service captured all NFOD events. During followup (where we had data for the same length of time in all datasets), ED data captured the highest proportion of medically-verified NFOD events (68\%). However, of the three medical services included, pre-release medically verified ambulance attendance for NFOD (in people both with and without self-reported history of NFOD) proved to be the strongest predictor of post-release NFOD resulting in medical care. Further research should examine the high rates of NFOD in those who utilise ambulance services following NFOD and develop strategies to engage them with overdose prevention and intervention.

\subsection{Strengths and limitations}

A unique strength of this study is the use of three administrative data sources to ascertain medically-verified NFOD events. Combining these administrative data with rich baseline interview data allowed us to create detailed models and adjust for many relevant covariates.

Our study had five main limitations. First, although representative of people being released from prisons in Queensland, the sample is unlikely to be representative of all those at risk of NFOD in the community. People in prison may have different motivations to report or not report NFOD, such as fears of further sanctions or surveillance, compared with people in the community. Therefore, the distribution of the four NFOD categories in our study may differ from that in the general population. Second, we did not have full medical histories for all participants. NFOD resulting in medical care could have occurred before our records commenced, resulting in under-ascertainment of medically-verified NFOD events. Third, we did not have access to toxicology reports and therefore we were not able to determine the prevalence of various drug classes in NFOD. Fourth, NFOD which were not reported and did not result in medical care would not have been captured. Finally, we did not capture medical service use occurring outside of Queensland. However, research on interstate hospital use in Australia estimates that the proportion of participants who obtain care outside of Queensland is $3 \%$, although it may be greater for marginalised and transient sub-populations (Spilsbury et al., 2015). Most limitations of our study would have resulted in under-ascertainment of NFOD events, and thus our estimates of effect are likely conservative.

\section{Conclusions}

Relying on self-report of NFOD may miss people at high risk of future NFOD who could be identified through medical records. However, medical records may also miss people who are susceptible to future NFOD who have not yet come into contact with health services for NFOD. Using data from any single medical service will under-ascertain NFOD resulting in medical care. Wherever possible, data related to NFOD should be triangulated from multiple sources. 


\subsection{Contributors}

SK developed the original research proposal and study design. CK and JY developed the study methodology and CK conducted the statistical analysis with contributions from JY. CK wrote the initial draft manuscript. JY, SK, and RB contributed significantly to the interpretation and synthesis of results and were involved with the development of the final manuscript submitted. CK had full access to the data used in this study and takes responsibility for the integrity of the data and accuracy of the data analysis. All authors have approved the final article.

\section{Role of funding source}

The Passports study was funded by National Health and Medical Research Council (NHMRC) Strategic AwardAPP409966 and NHMRC Project GrantAPP1002463. Stuart Kinner is supported by NHMRC Senior Research FellowshipAPP1078168. Rohan Borschmann is supported by NHMRC Early Career FellowshipAPP1104644. Jesse Young is supported by a Melbourne Research Scholarship (PhD) from the University of Melbourne. The funding source had no additional role in the research design; data collection, analysis, or interpretation; the writing of the manuscript; or the decision to submit the article for publication.

\section{Declaration of Competing Interest}

None.

\section{Acknowledgements}

The authors would like to acknowledge the Passports project team and the late Professor Konrad Jamrozik, for his pivotal role in conceiving and designing the Passports study. The authors also wish to acknowledge the Passports study participants for sharing their stories with us. The authors would like to acknowledge the assistance provided by Queensland Corrective Services to the Passports study. The views expressed herein are solely those of the authors, and in no way reflect the views or policies of Queensland Corrective Services.

\section{Appendix A. Supplementary data}

Supplementary material related to this article can be found, in the online version, at doi:https://doi.org/10.1016/j.drugalcdep.2019. 107742 .

\section{References}

Andersen, P.K., Gill, R.D., 1982. Cox's regression model for counting processes: a large sample study. Ann. Stat. 4, 1100

Australian Institute of Health and Welfare, 2016. Admitted Patient Care 2014-15: Australian Hospital Statistics. AIHW, Canberra.

Banjo, O., Tzemis, D., Al-Qutub, D., Amlani, A., Kesselring, S., Buxton, J.A., 2014. A quantitative and qualitative evaluation of the British Columbia Take Home Naloxone program. CMAJ Open 2 (3), E153-E161.

Banta-Green, C.J., Coffin, P.O., Merrill, J.O., Sears, J.M., Dunn, C., Floyd, A.S., Whiteside, L.K., Yanez, N.D., Donovan, D.M., 2019. Impacts of an opioid overdose prevention intervention delivered subsequent to acute care. Inj. Prev. 25 (3), 191.

Bennett, A.S., Bell, A., Tomedi, L., Hulsey, E.G., Kral, A.H., 2011. Characteristics of an overdose prevention, response, and naloxone distribution program in Pittsburgh and Allegheny County, Pennsylvania. J. Urban Health 88 (6), 1020-1030.

Best, D., Gossop, M., Man, L.-H., Finch, E., Greenwood, J., Strang, J., 2000. Accidental and deliberate overdose among opiate addicts in methadone maintenance treatment: are deliberate overdoses systematically different? Drug Alcohol Rev. 19 (2), 213-216.

Binswanger, I.A., Stern, M.F., Deyo, R.A., Heagerty, P.J., Cheadle, A., Elmore, J.G., Koepsell, T.D., 2007. Release from prison: a high risk of death for former inmates. N. Engl. J. Med. 356 (2), 157-165.

Boyd, J.H., Ferrante, A.M., O'Keefe, C.M., Bass, A.J., Randall, S.M., Semmens, J.B., 2012. Data linkage infrastructure for cross-jurisdictional health-related research in Australia. BMC Health Serv. Res. 12, 480.

Brugal, M.T., Barrio, G., Fuente, L.D.L., Regidor, E., Royuela, L., Suelves, J.M., 2002.
Factors associated with non-fatal heroin overdose: assessing the effect of frequency and route of heroin administration. Addiction 97 (3), 319-327.

Caudarella, A., Dong, H., Milloy, M.J., Kerr, T., Wood, E., Hayashi, K., 2016. Non-fatal overdose as a risk factor for subsequent fatal overdose among people who inject drugs. Drug Alcohol Depend. 162, 51-55.

Centers for Disease Control and Prevention, 2013. Prescription Drug Overdose Data and Statistics: Guide to ICD-9-CM and ICD-10 Codes Related to Poisoning and Pain. CDC, Atlanta, Georgia.

Centers for Disease Control and Prevention, 2017. Annual surveillance report of drugrelated risks and outcomes: United States, 2017. In: U.D.o.H.a.H (Ed.), Services. Centers for Disease Control and Prevention.

Chen, G., Faris, P., Hemmelgarn, B., Walker, R.L., Quan, H., 2009. Measuring agreement of administrative data with chart data using prevalence unadjusted and adjusted kappa. BMC Med. Res. Methodol. 9, 5.

Cicchetti, D.V., Feinstein, A.R., 1990. High agreement but low kappa: II. Resolving the paradoxes. J. Clin. Epidemiol. 43 (6), 551-558.

Coffey, C., Veit, F., Wolfe, R., Cini, E., Patton, G.C., 2003. Mortality in young offenders: retrospective cohort study. BMJ 326 (7398), 1064.

Coffin, P.O., Tracy, M., Bucciarelli, A., Ompad, D., Vlahov, D., Galea, S., 2007. Identifying injection drug users at risk of nonfatal overdose. Acad. Emerg. Med. 14 (7), 616-623.

Colledge, S., Peacock, A., Leung, J., Larney, S., Grebely, J., Hickman, M., Cunningham, E., Trickey, A., Stone, J., Vickerman, P., Degenhardt, L., 2019. The prevalence of nonfatal overdose among people who inject drugs: a multi-stage systematic review and meta-analysis. Int. J. Drug Policy.

Darke, S., 1998. Self-report among injecting drug users : a review. Drug Alcohol Depend. 51, 253-263.

Darke, S., Kaye, S., McKetin, R., Duflou, J., 2008. Major physical and psychological harms of methamphetamine use. Drug Alcohol Rev. 27 (3), 253-262.

Darke, S., Marel, C., Mills, K.L., Ross, J., Slade, T., Burns, L., Teesson, M., 2014. Patterns and correlates of non-fatal heroin overdose at 11-year follow-up: findings from the Australian Treatment Outcome Study. Drug Alcohol Depend. 144, 148-152.

Darke, S., Ross, J., 1996. Overdose among heroin users in Sydney, Australia: I. Prevalence and correlates of non-fatal overdose. Addiction 91 (3), 405-411.

Darke, S., Williamson, A., Ross, J., Mills, K.L., Havard, A., Teesson, M., 2007. Patterns of nonfatal heroin overdose over a 3-year period: findings from the Australian treatment outcome study. J. Urban Health 84 (2), 283-291.

Davidson, P.J., Ochoa, K.C., Hahn, J.A., Evans, J.L., Moss, A.R., 2002. Witnessing heroinrelated overdoses: the experiences of young injectors in San Francisco. Addiction 97 (12), 1511-1516.

Degenhardt, L., Darke, S., Dillon, P., 2003. The prevalence and correlates of gammahydroxybutyrate (GHB) overdose among Australian users. Addiction 98 (2), 199-204.

Dietze, P.M., Cvetkovski, S., Rumbold, G., Miller, P., 2000. Ambulance attendance at heroin overdose in Melbourne: the establishment of a database of Ambulance Service records. Drug Alcohol Rev. 19 (1), 27-33.

Enteen, L., Bauer, J., McLean, R., Wheeler, E., Huriaux, E., Kral, A.H., Bamberger, J.D., 2010. Overdose prevention and naloxone prescription for opioid users in San Francisco. J. Urban Health 87 (6), 931-941.

Fischer, B., Brissette, S., Brochu, S., Bruneau, J., el-Guebaly, N., Noël, L., Rehm, J., Tyndall, M., Wild, C., Mun, P., Haydon, E., Baliunas, D., 2004. Determinants of overdose incidents among illicit opioid users in 5 Canadian cities. Canad. Med. Assoc. 171 (3), 235-239.

Forsyth, S.J., Carroll, M., Lennox, N., Kinner, S.A., 2018. Incidence and risk factors for mortality after release from prison in Australia: a prospective cohort study. Addiction $5,937$.

Gunasekaran, B., Weil, J., Whelan, T., Santamaria, J., Boughey, M., 2018. Assessment of potential opioid toxicity and response to naloxone by rapid response teams at an urban Melbourne hospital. Intern. Med. J. 48 (2), 198-200.

Hakansson, A., 2008. Factors associated with history of non-fatal overdose among opioid users in the Swedish criminal justice system. Drug Alcohol Depend. 94, 48-55.

Hobbs, M., Ridout, S., Mai, Q., Krazlan, K., Chapman, R., Knuiman, M., 2006. Mortality and morbidity in prisoners after release from prison in Western Australia 1995-2003. Trends Issues Crime Criminal Justice 320, 1-6.

Jenkins, L.M., Banta-Green, C.J., Maynard, C., Kingston, S., Hanrahan, M., Merrill, J.O., Coffin, P.O., 2011. Risk factors for nonfatal overdose at Seattle-area syringe exchanges. J. Urban Health 88 (1), 118-128.

Kaye, S., Darke, S., 2004. Non-fatal cocaine overdose among injecting and non-injecting cocaine users in Sydney, Australia. Addiction 99 (10), 1315-1322.

Kerr, T., Fairbairn, N., Tyndall, M., Marsh, D., Li, K., Montaner, J., Wood, E., 2007. Predictors of non-fatal overdose among a cohort of polysubstance-using injection drug users. Drug Alcohol Depend. 87, 39-45.

Kinner, S., Milloy, M.-J., Wood, E., Qi, J., Zhang, R., Kerr, T., 2012. Incidence and risk factors for non-fatal overdose among a cohort of recently incarcerated illicit drug users. Addict. Behav. 37, 691-696.

Kinner, S.A., Degenhardt, L., 2008. Crystal methamphetamine smoking among regular ecstasy users in Australia: increases in use and associations with harm. Drug Alcohol Rev. 27 (3), 292-300.

Kinner, S.A., Lennox, N., Williams, G.M., Carroll, M., Quinn, B., Boyle, F.M., Alati, R., 2013. Randomised controlled trial of a service brokerage intervention for ex-prisoners in Australia. Contemp. Clin. Trials 36 (1), 198-206.

Lake, S., Hayashi, K., Milloy, M.J., Wood, E., Dong, H., Montaner, J., Kerr, T., 2015. Associations between childhood trauma and non-fatal overdose among people who inject drugs. Addict. Behav. 43, 83-88.

Landis, J.R., Koch, G.G., 1977. The measurement of observer agreement for categorical data. Biometrics 33 (1), 159-174.

Larney, S., Burns, L., 2011. Evaluating health outcomes of criminal justice populations using record linkage: the importance of aliases. Eval. Rev. 35 (2), 118-128. 
Lawrence, G., Dinh, I., Taylor, L., 2008. The Centre for Health Record Linkage: a new resource for health services research and evaluation. Health Inf. Manag. J. 37 (2), 60-62.

Lloyd, J.E., McEntyre, E., Baldry, E., Trofimovos, J., Indig, D., Abbott, P., Reath, J., Malera-Bandjalan, K., Harris, M.F., 2017. Aboriginal and non-aboriginal Australian former prisoners' patterns of morbidity and risk of hospitalisation. Internal 16 (3).

Looney, S.W., Hagan, J.L., 2007. 4 statistical methods for assessing biomarkers and analyzing biomarker data. In: Rao, C.R., Miller, J.P., Rao, D.C. (Eds.), Handbook of Statistics. Elsevier, pp. 109-147.

MacDougall, L., Smolina, K., Otterstatter, M., Zhao, B., Chong, M., Godfrey, D., MussaviRizi, A., Sutherland, J., Kuo, M., Kendall, P., 2019. Development and characteristics of the Provincial Overdose Cohort in British Columbia, Canada. PLoS One 14 (1), e0210129.

Maloney, E., Degenhardt, L., Darke, S., Nelson, E.C., 2009. Are non-fatal opioid overdoses misclassified suicide attempts? Comparing the associated correlates. Addict. Behav. 34, 723-729.

Martins, S.S., Sampson, L., Cerdá, M., Galea, S., 2015. Worldwide prevalence and trends in unintentional drug overdose: a systematic review of the literature. Am. J. Public Health 105 (11), 2373.

Massachusetts Department of Public Health, 2017. An Assessment of Fatal and Nonfatal Opioid Overdoses in Massachusetts (2011-2015), Legislative Report: Chapter 55 Opioid Overdose Study. Massachusetts Department of Public Health, Massachusetts, USA.

McGregor, C., Darke, S., Ali, R., Christie, P., 1998. Experience of non-fatal overdose among heroin users in Adelaide, Australia: circumstances and risk perceptions. Addiction 93 (5), 701.

Mesquita, F., Kral, A., Reingold, A., Haddad, I., Sanches, M., Turienzo, G., Piconez, D., Araujo, P., Bueno, R., 2001. Overdoses among cocaine users in Brazil. Addiction 96 (12), 1809-1813.

Milloy, M., Fairbairn, N., Hayashi, K., Suwannawong, P., Kaplan, K., Wood, E., Kerr, T., 2010. Overdose experiences among injection drug users in Bangkok, Thailand. Harm. Reduct. J. 7 (9).

Milloy, M.J.S., Kerr, T., Mathias, R., Zhang, R., Montaner, J.S., Tyndall, M., Wood, E., 2008. Non-fatal overdose among a cohort of active injection drug users recruited from a supervised injection facility. Am. J. Drug Alcohol Abuse 34 (4), 499-509.

Moore, E., Winter, R., Indig, D., Greenberg, D., Kinner, S., 2013. Non-fatal overdose among adult prisoners with a history of injecting drug use in two Australian states. Drug Alcohol Depend. 133, 45-51.

Neale, J., Robertson, M., 2005. Recent life problems and non-fatal overdose among heroin users entering treatment. Addiction 100 (2), 168-175.

Nosrati, E., Kang-Brown, J., Ash, M., McKee, M., Marmot, M., King, L.P., 2019. Economic decline, incarceration, and mortality from drug use disorders in the USA between 1983 and 2014: an observational analysis. Lancet Public Health 4 (7), e326-e333.

Ochoa, K.C., Davidson, P.J., Evans, J.L., Hahn, J.A., Page-Shafer, K., Moss, A.R., 2005 Heroin overdose among young injection drug users in San Francisco. Drug Alcohol Depend. 80 (3), 297-302.

Piper, T.M., Stancliff, S., Rudenstine, S., Sherman, S., Nandi, V., Clear, A., Galea, S., 2008. Evaluation of a naloxone distribution and administration program in New York City. Subst. Use Misuse 43 (7), 858-870.

Pollini, R.A., McCall, L., Mehta, S.H., Vlahov, D., Strathdee, G., 2006. Non-fatal overdose and subsequent drug treatment among injection drug users. Drug Alcohol Depend. 83, 104-110.

Powis, B., Strang, J., Griffiths, P., Taylor, C., Williamson, S., Fountain, J., Gossop, M., 1999. Self-reported overdose among injecting drug users in London: extent and nature of the problem. Addiction 94 (4), 471-478.

Preen, D.B., Holman, C.D.A.J., Lawrence, D.M., Baynham, N.J., Semmens, J.B., 2004 Hospital chart review provided more accurate comorbidity information than data from a general practitioner survey or an administrative database. J. Clin. Epidemiol. 57 (12), 1295-1304.

Provincial Health Services Authority, 2019. Community Transition Teams Aim to Prevent Overdose Deaths Among People Recently Released From a Correctional Facility.

(Accessed 18 June 2019). http://www.bcmhsus.ca/news/Pages/Community- transition-teams-aim-to-prevent-overdose-deaths-among-people-recently-releasedfrom-a-correctional-facility.aspx.

Rafful, C., Orozco, R., Rangel, G., Davidson, P., Werb, D., Beletsky, L., Strathdee, S.A., 2018. Increased non-fatal overdose risk associated with involuntary drug treatment in a longitudinal study with people who inject drugs. Addiction 113 (6), 1056-1063.

Ray, B.R., Lowder, E.M., Kivisto, A.J., Phalen, P., Gil, H., 2018. EMS naloxone administration as non-fatal opioid overdose surveillance: 6-year outcomes in Marion County, Indiana. Addiction 113 (12), 2271-2279.

Reardon, J.M., Harmon, K.J., Schult, G.C., Staton, C.A., Waller, A.E., 2016. Use of diagnosis codes for detection of clinically significant opioid poisoning in the emergency department: a retrospective analysis of a surveillance case definition. BMC Emerg. Med. 16, 1-6.

Rowe, C., Vittinghoff, E., Santos, G.-M., Behar, E., Turner, C., Coffin, P.O., 2017. Performance measures of diagnostic codes for detecting opioid overdose in the emergency department. Acad. Emerg. Med. 24 (4), 475-483.

Seal, K.H., Downing, M., Kral, A.H., Singleton-Banks, S., Hammond, J.-P., Lorvick, J. Ciccarone, D., Edlin, B.R., 2003. Attitudes about prescribing take-home naloxone to injection drug users for the management of heroin overdose: a survey of street-recruited injectors in the San Francisco Bay Area. J. Urban Health 80 (2), 291-301.

Šidák, Z., 1967. Rectangular confidence regions for the means of multivariate normal distributions. J. Am. Stat. Assoc. 62 (318), 626-633.

Slavova, S., Bradley O'brien, D., Creppage, K., Dao, D., Fondario, A., Haile, E., Hume, B. Largo, T.W., Nguyen, C., Sabel, J.C., Wright, D., 2015. Drug overdose deaths: let's get specific. Public Health Rep. 130 (4), 339-342.

Slavova, S., Bunn, T., Talbert, J., 2014. Drug overdose surveillance using hospital discharge data. Public Health Rep. 129 (5), 437-445.

Spilsbury, K., Rosman, D., Alan, J., Boyd, J.H., Ferrante, A.M., Semmens, J.B., 2015. Cross border hospital use: analysis using data linkage across four Australian states. Med. J. Aust. 202 (11), 582-586.

StataCorp, 2015. Stata Statistical Software: Release 14. StataCorp LP, College Station, TX.

Stoové, M.A., Dietze, P.M., Jolley, D., 2009. Overdose deaths following previous non-fatal heroin overdose: record linkage of ambulance attendance and death registry data. Drug Alcohol Rev. 28 (4), 347-352.

Strang, J., Bird, S.M., Parmar, M.K., 2013. Take-home emergency naloxone to prevent heroin overdose deaths after prison release: rationale and practicalities for the $\mathrm{N}$ ALIVE randomized trial. J. Urban Health 90 (5), 983-996.

Sumner, S.A., Mercado-Crespo, M.C., Spelke, M.B., Paulozzi, L., Sugerman, D.E., Hillis, S.D., Stanley, C., 2016. Use of naloxone by emergency medical services during opioid drug overdose resuscitation efforts. Prehospital Emerg. Care 20 (2), 220-225.

Tibble, H., Law, H.D., Spittal, M.J., Karmel, R., Borschmann, R., Hail-Jares, K., Thomas, L.A., Kinner, S.A., 2018. The importance of including aliases in data linkage with vulnerable populations. BMC Med. Res. Methodol. 18 (1), 76.

Tobin, K.E., Sherman, S.G., Beilenson, P., Welsh, C., Latkin, C.A., 2009. Evaluation of the staying Alive programme: training injection drug users to properly administer naloxone and save lives. Int. J. Drug Policy 20 (2), 131-136.

Tracy, M., Piper, T.M., Ompad, D., Bucciarelli, A., Coffin, P.O., Vlahov, D., Galea, S., 2005. Circumstances of witnessed drug overdose in New York City: implications for intervention. Drug Alcohol Depend. 79 (2), 181-190.

Wakeman, S.E., Bowman, S.E., McKenzie, M., Jeronimo, A., Rich, J.D., 2009. Preventing death among the recently incarcerated: an argument for naloxone prescription before release. J. Addict. Dis. 28 (2), 124-129.

Winter, R.J., Stoové, M., Degenhardt, L., Hellard, M.E., Spelman, T., Jenkinson, R., McCarthy, D.R., Kinner, S.A., 2015. Incidence and predictors of non-fatal drug overdose after release from prison among people who inject drugs in Queensland, Australia. Drug Alcohol Depend. 153, 43-49.

World Health Organization, 2013. Good Governance for Prison Health in the 21st Century: a Policy Brief on the Organization of Prison Health. The Regional Office for Europe of the World health Organization, Copenhagen.

Yin, L., Qin, G., Ruan, Y., Qian, H.-Z., Hao, C., Xie, L., Chen, K., Zhang, Y., Xia, Y., Wu, J., Lai, S., Shao, Y., 2007. Nonfatal overdose among heroin users in Southwestern China. Am. J. Drug Alcohol Abuse 33 (4), 505-516. 